\title{
Coastal Climate Adaptation Literatures of the Southeast and Northeast U.S.: Regional Comparisons among States and Document Sources
}

\author{
Kenyon C. Lindeman ${ }^{1, *}$, Christos Giannoulis ${ }^{2}$ and Bryce R. Beard ${ }^{3}$ \\ 1 Sustainability Studies Program, Florida Institute of Technology, Melbourne, FL 32937, USA \\ 2 Institutional Research, Valencia College, Orlando, FL 32811, USA; cgiannoulis@valenciacollege.edu \\ 3 Penn State Dickinson Law School, Carlisle, PA 17013, USA; bbeard1992@gmail.com \\ * Correspondence: lindeman@fit.edu; Tel.: +1-321-271-7547
}

Received: 31 October 2018; Accepted: 8 December 2018; Published: 11 December 2018

\begin{abstract}
Challenges remain in optimizing the use of increasingly large inflows of climate adaptation articles and guidance documents to improve coastal science and engineering practices. In addition to four major academic databases, the large grey literature was quantified by analyzing web sources of hundreds of government, nonprofit and university reports not previously included in reviews. Three spatial scales were examined for differences in amount and timing of adaptation documents: (a) between region (southeast and northeast U.S.); (b) among sub-region (Florida and Carolinas; New York/New Jersey and New England); and (c) among states (ten states total). Comparisons were also made across spatial scales for document sources (academic journals, government, non-governmental organizations (NGO), university, mixed sources), including four governance subcategories (federal, state, regional and local). Differences were identified among some spatial scales in academic vs. grey literature and among categories of grey literature. $53 \%$ of the literature was from grey sources ( $21 \%$ government, $10 \%$ university, $8 \%$ nonprofit and $14 \%$ mixed sources). This literature can be large and is grounded in applied, experiential knowledge, yet is unavailable in almost all academic databases. These relatively hidden documents provide insight into on-the-ground science and engineering case-histories, policy innovations, and power relationships across scales of geography and governance.
\end{abstract}

Keywords: coastal; adaptation; climate; government; sea level; resilience; grey literature

\section{Introduction}

Future coastal flooding will affect the southeast and northeast U.S with exceptionally costly alternatives for vulnerable coastal populations in states like Florida, New York and others [1,2]. The economic stakes at play are exceptional, with New York and Florida alone representing the 12th and 17th largest country-scale GDPs globally [3]. Increasing effects of climate change will manifest in accelerating sea level rises and larger storm-related flooding events [4], with complex factors that foster or constrain the uptake of climate adaptation in part due to differing spatial scales and information sources [5].

The interface between the burgeoning literature output and actual coastal climate adaptation advances is clearly important to trans-disciplinary applications of policy, science, and engineering, yet is under-examined. Despite a half-century of concerted research in climate change, many local governments have long faced challenges in efforts to design or implement climate adaptation programs [6-8]. This is reflected in part by the escalation of disaster losses and the increasing prices of insurance in at-risk areas, features that will increase with time and rising sea levels $[9,10]$. 
The importance of information dispersal in coastal adaptation across multiple stakeholder groups is examined by References [11,12].

There have been large increases in the amounts and sources of climate adaptation reports and guides with utility across many research fronts. Given the potential value of optimally used literature to adaptation decision-makers, the size and diversity of the growing literature has created a diverse, parallel literature of systematic reviews [13]. This trend is reflected by systematic reviews of adaptation topics including knowledge and power in governance [14], planning for mangrove ecosystems [15], local vulnerability research [16], and multiple stressor effects on human vulnerability [17].

Geographic regions are another common focus of climate adaptation literature reviews, including developed nations [18], Ghana [19], the Canadian Arctic [20] and households in the UK [21]. Systematic reviews have been done on many types of adaptation websites with findings including the use of web databases and the degree in which the sites may catalyze adaptive actions [22,23].

The amount and quality of the grey literature on climate adaptation (i.e., not formally peer- reviewed in an academic journal), including valuable government, NGO, and university consulting reports, is substantial but not fully integrated into climate adaptation systematic review processes [24,25]. Reference [13] reviewed 27 systematic reviews of climate adaptation topics using Web of Knowledge. Nine identified articles total used grey literature and only one reviewed both grey literature as well as academic, peer-reviewed literature [26].

Basing a comprehensive review only on academic databases can exclude many relevant adaptation reports by government agencies, nonprofits, universities and other non-academic sources that can shed light on applied local government adaptation. For example, detailed stormwater planning guides for public works departments on the front-lines of city sea level rise [27] for Pompano Beach, Florida. Hundreds of coastal adaptation reports like this one are not returned by academic database searches.

Disengagements between adaptation planning and applied policy were noted in the National Climate Assessment [28]: "Adaptation planning is occurring in the public and private sectors and at all levels of government but few measures have been implemented." Mainstreaming and implicit adoption of adaptation best practices (e.g., [29]) are other reasons the grey literature can have such value. The government, NGO, and university literatures not captured in academic databases can have major real-world applications given this work is more often grounded in the adaptation experiences of local through federal government or advocacy actors, often in landscapes with differing ideologies and power relationships (e.g., [30]).

Given the challenges in identifying and implementing best practices to process the continuous inflows of reports on coastal adaptation, this project examined spatial and temporal attributes of the climate adaptation literatures of the southeast and northeast regions of the U.S. Atlantic coast using systematic review practices. In addition to academic databases, websites including government, NGO, and university reports were quantified temporally and at three spatial scales. Research questions were: are differences present in the amount and timing of appearance of coastal adaptation reports: (a) among regions (southeast and northeast U.S.); (b) among sub-regions (Florida and Carolinas, New York/New Jersey and New England); (c) among differing states (ten total); and (d) among differing literature sources (five source categories, with four government subcategories).

\section{Methods}

\subsection{Study Areas}

Figure 1 shows the distribution of states examined at three spatial scales. The largest scale has two regions; (1) the Southeast U.S. (SE) and (2) Northeast U.S. (NE). At an intermediate scale, the SE includes two sub-regions: (1) Florida and (2) Carolinas (South and North Carolina) and the NE region, also with two sub-regions: (1) New York/New Jersey and (2) New England (Connecticut, Massachusetts, Maine, Rhode Island and New Hampshire). At the finest scale, there were ten states total (three in the SE, seven in the NE) (Figure 1). We emphasized the northernmost and southernmost 
regions to compare the most distinct U.S. Atlantic coastal areas feasible and to keep highly abundant search results and diverse comparisons manageable (including several academic databases and grey literature from multiple sources).

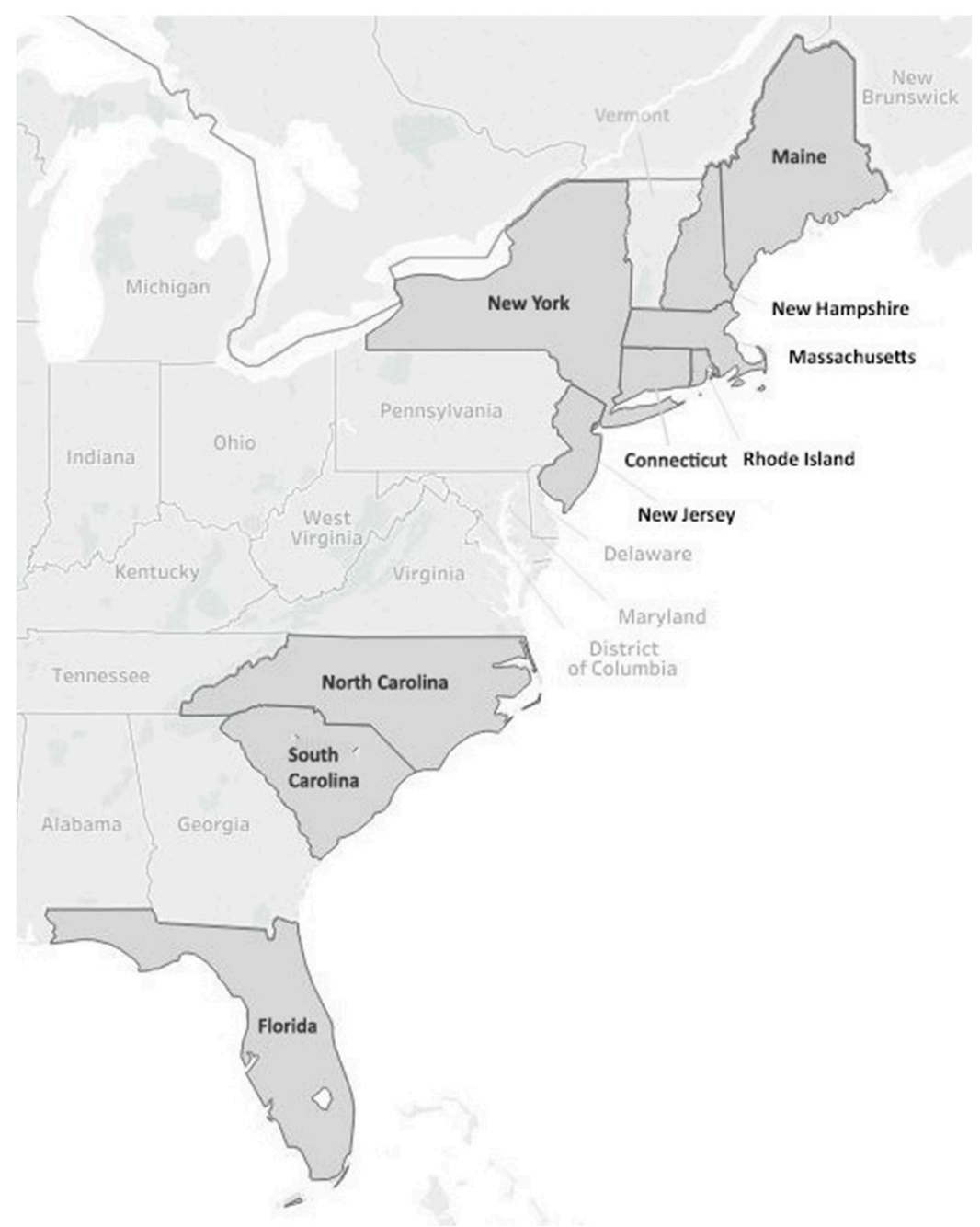

Figure 1. States surveyed in the southeast and northeast United States.

\subsection{Databases and Processing Protocols}

We surveyed academic databases using standard systematic review protocols $[13,16]$ to examine potential differences in the number of reports and articles on climate adaptation among three differing spatial scales and diverse categories of sources over time. The academic databases used were Web of Science, Scopus, ProQuest, and Academic Search Complete. Analyses compared all spatial scales: regions, sub-regions, and states as outlined above.

We sampled additional, non-academic web databases of adaptation information to be comprehensive. Non-academic database (non-journal) literature was primarily obtained using online adaptation databases which collect government, NGO, and university adaptation reports documents as well as academic journal articles. The all-source databases we used were the Coastal Climate Adaptation Library (formerly Virtual Climate Adaptation Library) and the Climate Adaptation Knowledge Exchange, primarily the former. Both websites contain peer-review literature as well as large amounts of professional, non-peer-reviewed grey literature. Terms and concepts associated with climate adaptation and related concepts of resilience have evolved rapidly with various meanings and interpretations. We followed 
the National Climate Assessment [28]: "Adaptation refers to action to prepare for and adjust to new conditions, thereby reducing harm or taking advantage of new opportunities".

The search protocol is outlined in the flowchart that guided review of the amount and diversity of documents retrieved for the ten project states (Figure 2). Inclusion and exclusion criteria for reports returned from the search are in Table S1. Based on academic database specifics, these search terms were used: Web of Science: Accessed 4/16/2015, "STATE" AND "climat* change" AND adapt*-Topic. Academic Search Complete: Accessed 4/16/2015, "STATE" AND "climat* change" AND adapt*-All Fields. ProQuest: Accessed 4/15/2015, All ("STATE" AND "climat* change" AND adapt*); Scopus: Accessed 4/16/2015; TITLE-ABS-KEY ("STATE" AND "climat* change" AND adapt*). To examine each of the study states, the term "State" in each search was replaced with the names of each of the states in Figure 1. The citations for these articles are in Table S2.

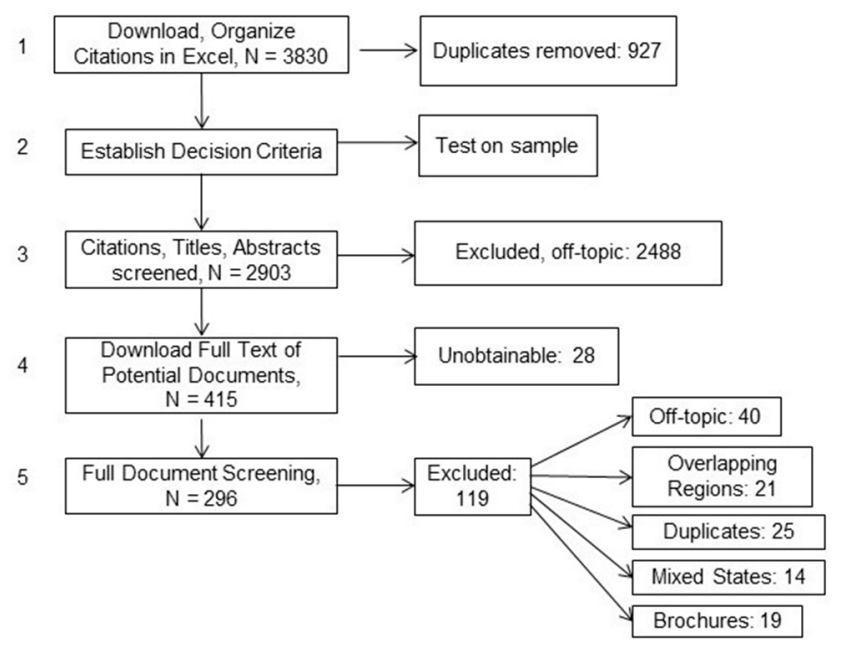

Figure 2. Summary of steps in document search and review sequence.

\subsection{Adaptation Reports by Spatial Scale and Type of Database}

Using the documents available after Step 5 of the protocol (Figure 2), we tallied documents from state level up through higher spatial scales and into Academic Databases or All-source Databases for document sources. Differences in the number of reports were examined among three spatial scales: Regions ( 2 comparisons), sub-regions $(4,2+2)$, and states (10 total; 3 South, 7 North) and across time in years. The regional scale comparison was between the SE U.S. and NE U.S. Sub-regions compared within the SE U.S. were Florida and the Carolinas (South and North Carolina). The individual southeast state comparisons were among Florida, South Carolina and North Carolina. Sub-region comparisons within the NE U.S. were between New York/New Jersey (NY/NJ) and New England (NE). The individual northeast state-scale comparisons were among New York (NY), New Jersey (NJ), Connecticut (CT), Massachusetts (MA), Rhode Island (RI), New Hampshire (NH) and Maine (ME).

\subsection{Adaptation Reports by Spatial Scale and Document Source}

The second research question compared the differing sources of reports and articles on climate adaptation across the three spatial scales over time. Differing sources of documents were quantified as well among differing databases and sources within. Five individual categories of document sources were identified:

1. Journals (J): peer-reviewed academic journals (J).

2. Government (GF, GS, GR, GL): policy reports prepared by or primarily funded by public sector entities, including local, state, and federal agencies. This category has at least four important governance subcategories: GF: Government Federal, federal planning and science agencies; GS: 
Government State, state planning and science agencies; GR: Government Regional, regional planning initiatives; GL: Government Local, city or county planning and administrative agencies.

3. NGOs (=nonprofits) (N): reports prepared by or primarily funded by NGO/non-profit organizations, typically not formally peer-reviewed as in academic journal publications.

4. Universities (U): reports prepared by universities, typically as contractors, often for other funding sources (e.g., GF, GS, N).

5. Mixed reports (M): Many combinations of sources can occur in the literature on adaptation and many reports are co-produced in writing, funding, or both by multiple institutional collaborators. For example, M: U, GS, when a university works with state government to produce a report.

\subsection{Data Analysis}

Test of Independence using the Chi-square statistic were conducted among three spatial scales. The broadest scale was regional: (a) Region (North and South) $\times$ Literature Type (Peer and Non-Peer Reviewed) and (b) Region $\times$ Document Source (Journals, NGO Reports, University Reports, Government Reports and Mixed Reports). The second scale was sub-regional: (a) Sub-region ((Florida and Carolinas; New England New York/New Jersey) $\times$ Literature Type and (b) Sub-region $\times$ Document Source. The finest scale was state: (a) State $(10$ total $) \times$ Literature Type, and (b) State $\times$ Document Source.

Prior to conducting analyses, the assumption of adequate cell size was assessed, all cells to have expected values greater than zero and $80 \%$ of cells to have expected values of at least five. When assumptions of the Chi-square test were violated, Fisher's exact test was used. When the Chi-square test is significant, suggesting that subjects are related to one another, the p-value does not indicate how this should affect interpretation. We used Bayes Factor contingency tables, which can estimate the relative strength of the association between two subjects [31].

\section{Results}

\subsection{Spatial Scales}

Overall, 310 documents were identified in the searches following the process and criteria in Figure 2 and Table S1. Using the documents available after Step 5 of the protocol, we tallied the document subtotals for Academic Databases or All-source Databases by state level up through the two higher spatial scales: sub-regions and regions. 139 reports were from academic databases (peer-reviewed) and 157 were from all-source databases (not subject to blind peer review). The Chi-square test of regions (Northeast U.S. [144 papers] and Southeast U.S. [154 papers]) and types of databases (academic and all-source databases) was not significant, $(\chi 2(1)=2.21, p=0.137)$ with little evidence for a difference in numbers of documents between these two regions of the U.S. Atlantic seaboard. Comparisons at sub-regional scales of reports in academic and all-source databases are summarized in Figure 3. 46\% of the reports were from all-source databases in Florida, and 39\% were from academic databases in New York state. In terms of sub-regions and types of databases, the Chi-square test was significant, $\chi 2(3)=11.25, p=0.010$ (Table S3), suggesting they were related to one another. The association was weak based on [32], Cramer's V $=0.086$. The Poisson GD74 Bayes Factor was obtained: $B F_{10}^{P}=8.9$, indicating moderate evidence for an association between the sub-region and the type of literature. Florida, with a larger shoreline and coastal economy than the Carolinas, had more documents from both academic and all-source databases. The following combinations had observed values that were greater than their expected values: Carolinas: All-source database, Florida: All-source Databases, New England: All-source databases, and New York \& New Jersey: Academic Databases. The following level combinations had observed values that were less than their expected values: New York \& New Jersey: All-source databases, Carolinas: Academic Databases, Florida: Academic Databases, and New England: Academic Databases. 


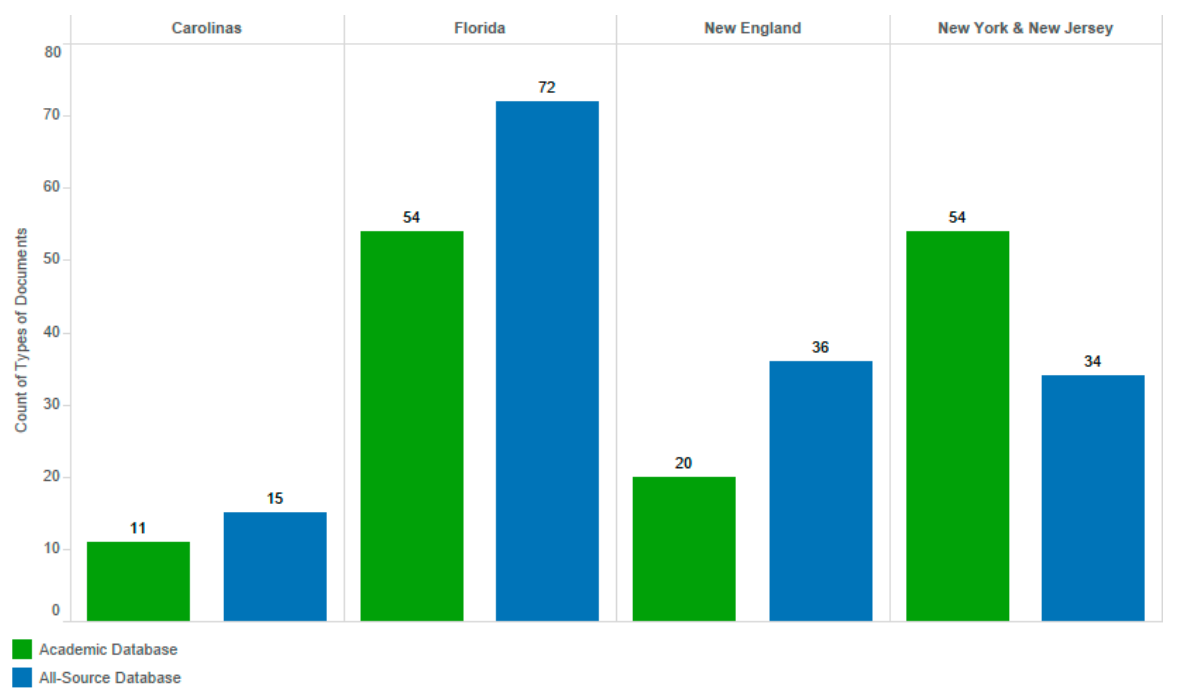

Figure 3. Sub-regional totals of adaptation literature returns by the two types of databases. SE U.S. sub-regions: Carolinas (CR) and Florida (FL). NE U.S. sub-regions: New England (NE) and New York/New Jersey (NY/NJ).

In comparing individual states by types of databases (academic or all-source) (Figure 4), the results of the Chi-square test were significant, $\chi 2(9)=36.99, p<0.001$, suggesting that state and source of document were related to one another. The association was medium, Cramer's V $=0.354$. The Poisson GD74 Bayes Factor was $B F_{10}^{P}=19,190$ indicating decisive evidence for the hypothesis that there was an association between state and types of databases. By region, Florida and New York were the dominant states in terms of literature. Florida had 72 all-source and 54 academic reports, conversely, New York differed with 20 and 43, respectively. New Jersey and Massachusetts ranked third and fourth of the remaining ten states.

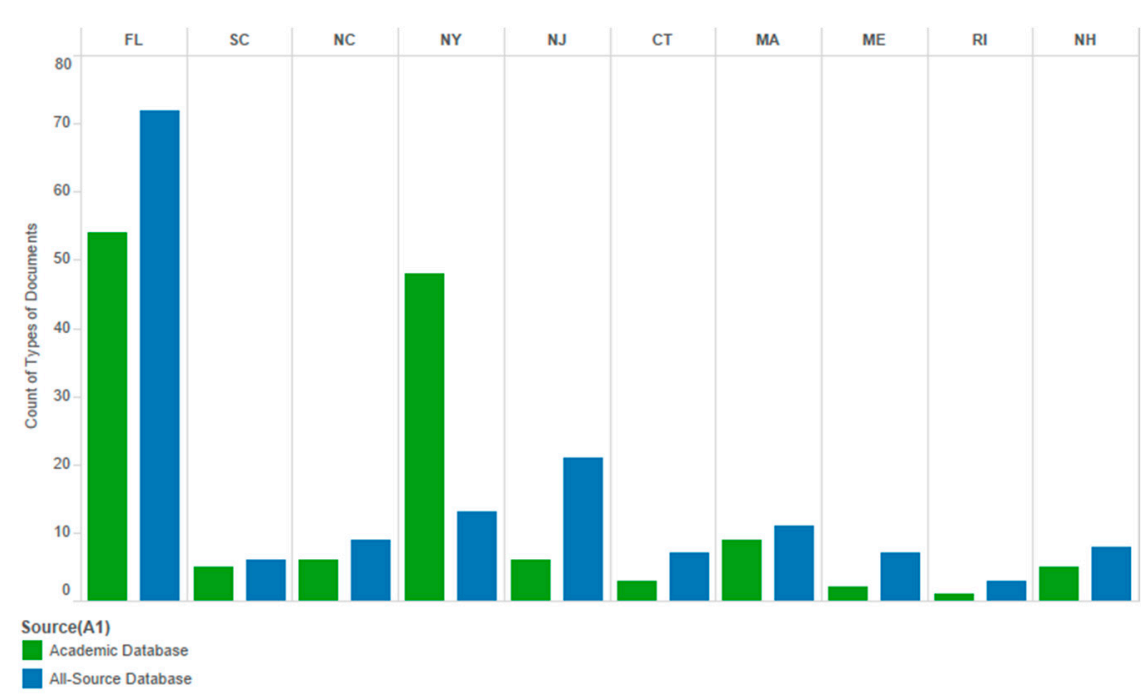

Figure 4. Paired comparisons of states and differing types of databases (academic and all-source databases) across ten U.S. east coast states.

The following level combinations had observed values that were greater than their expected values: CT: All-source Database (ASD), FL:ASD, MA:ASD, ME:ASD, NC:ASD, NH:ASD, NJ:ASD, RI:ASD, SC:ASD, and NY: Academic Database (AD). The following combinations had observed values that were less than their expected values: NY:ASD, CT:AD, FL:AD, MA:AD, ME:AD, NC:AD, NH:AD, $\mathrm{NJ}: \mathrm{AD}, \mathrm{RI}: \mathrm{AD}$, and SC:AD. 


\subsection{Temporal Patterns and Adaptation Literatures}

Temporal attributes of the developing literature for the U.S. East coast from 1980-2015 are summarized in Figure 5. The biggest increase in the number of reports was by 2007-2008 with more of almost all types of literature at all spatial scales which has maintained with increases through 2015. New York had a valuable and growing adaptation literature before Hurricane Sandy in 2011, increasing substantially by 2007 (Figure 5). The amount of adaptation literature in NY increased after 2011 (and in NJ and MA, also affected by Sandy). The earliest document retrieved was from 1984. This reflects an under-representation of older books and document sources (e.g., conference proceedings) by conventional search tools as there are various earlier documents that were not retrieved despite the broad search (e.g., see reference sections in chapters of Reference [33]).

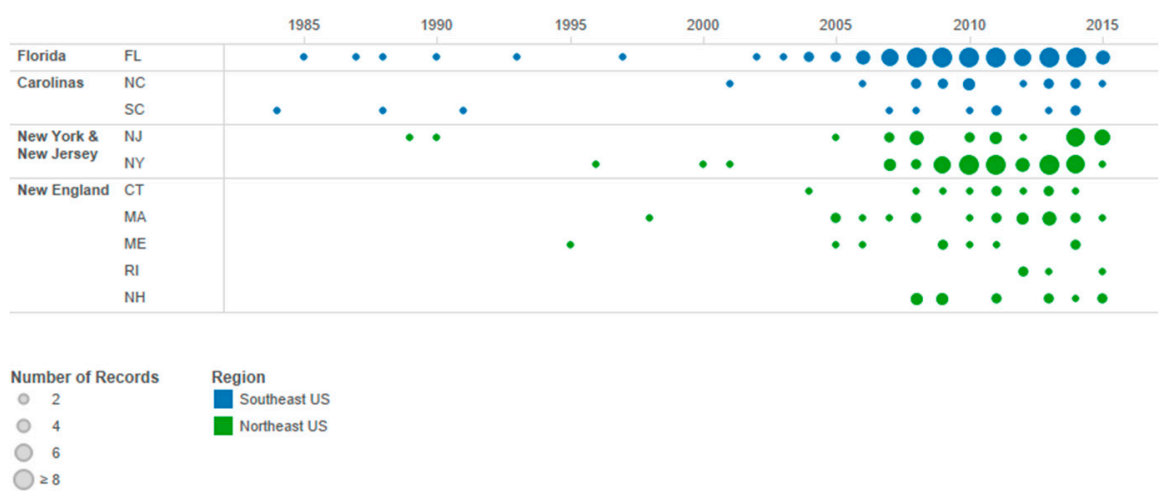

Figure 5. Spatial and temporal patterns of climate adaptation literature (pooled for academic and all-source databases) across Regions, Subregions, and States of the U.S. Atlantic coast, 1980-2015.

\subsection{Adaptation Reports by Spatial Scale and Document Source}

Comparisons of document sources stratified by U.S. east coast states and primary sources of documents are shown in Figure 6. Sources of non-academic reports included peer-reviewed journals (J), government sources (G), non-governmental organizations (NGO), universities (U), and, importantly, mixed combinations (M) of above sources. At the spatial scale of region (Northeast U.S. and Southeast U.S.) and document source (J, G, N, U, and M), the results of the Chi-square test were not significant, $\chi 2(4)=6.08, p=0.193$, suggesting regions and sources of documents were independent. The non-journal sources reflect under-sampled sources of documents from centers of expertise of climate adaptation knowledge in addition to journals. These other sources also reflect institutional mechanics in social-ecological systems, the functional units of management (e.g., [30]).

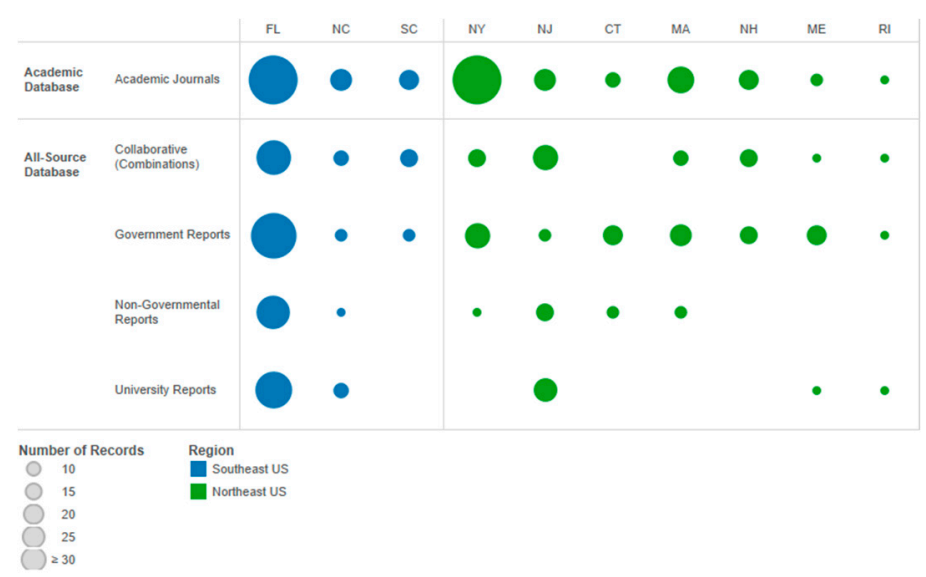

Figure 6. Adaptation literature by document sources across ten southeast and northeast U.S. states. 
At the sub-regional scale (Carolinas and Florida; New England and NY/NJ) by source of document, the Chi-square was significant, $\chi 2(12)=28.25, p=0.005$ (Table S4), suggesting these factors were related to one another in some comparisons. The Poisson GD74 Bayes Factor was $B F_{10}^{P}=15.08$ indicating very strong support for the hypothesis that there were associations between sub-regions and document sources. The following pairs of states and document sources had observed values that were greater than their expected values: Florida: Government, New England: Government, New York \& New Jersey: Journal, Carolinas: Mixed, New England: Mixed, Florida: NGO, Carolinas: University, and Florida: University. The following combinations had observed values that were less than their expected values: Carolinas: Government, New York \& New Jersey: Government, Carolinas: Journal, Florida: Journal, New England: Journal, Florida: Mixed, New York \& New Jersey: Mixed, Carolinas: NGO, New England: NGO, New York \& New Jersey: NGO, New England: University, and New York \& New Jersey: University.

At the scale of state and type of government document source (Figure 7), the results of the Fisher Exact test were significant, $\chi 2(198)=271.48, p<0.001$, suggesting that state and sources of documents were related to one another. The Poisson GD74 Bayes Factor was $\log B F_{10}^{P}=30.76$, indicated strong evidence for the hypothesis that there was an association. The most abundant source of adaptation materials was the large pool of government sources at local through federal scales (Figure 7); university reports (often contracted by and co-produced by government sources) were also relatively high in abundance.

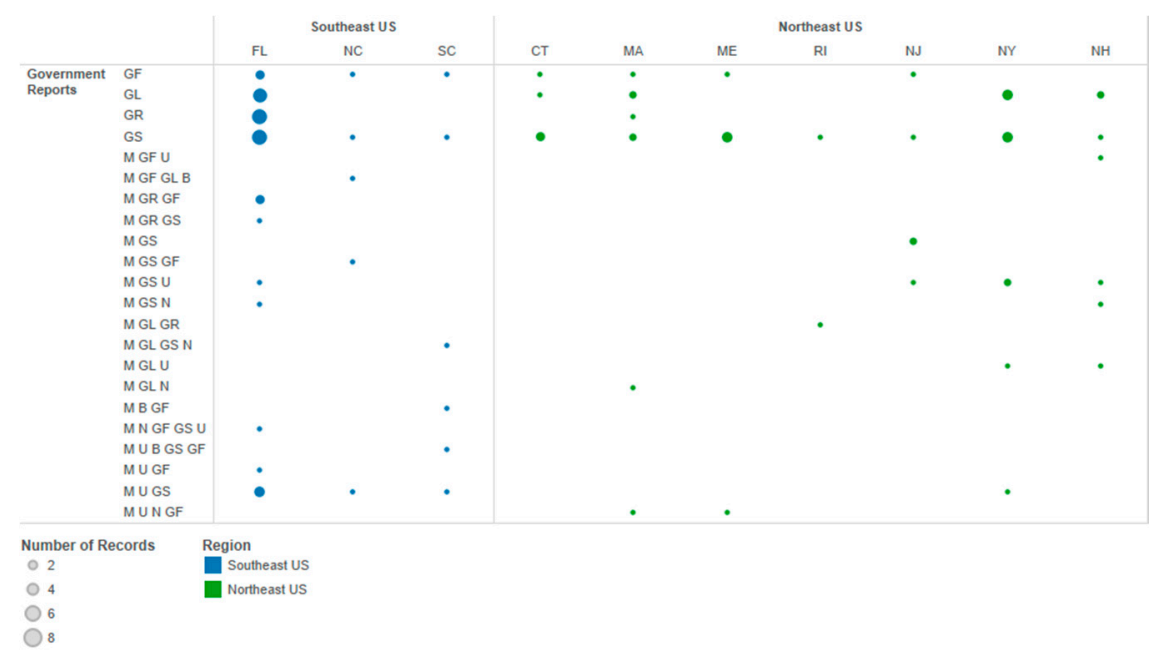

Figure 7. Multiple scales of government reports by state in four categories and eight subcategories from mixed sources. GF: government federal, GS: government state; GR: government regional; GL: government local. M: mixed-source report.

In the state with the most document retrievals, Florida had two to eight government documents at each subscale: local, regional, state and federal. New York and Massachusetts were also a substantial focus of a number of documents with government sources. There were more state government reports than any other subscale of government source (Figure 7), reflecting the importance of climate adaptation to many state-level agencies. These documents are often very applied, reflecting on-the-ground problem-solving in public policy; most will not be retrieved by searches of academic databases.

There were several documents from mixed sources of governmental agencies collaborating on a report (e.g., a federal and state agency) in all sub-regions and seven of the ten states. Florida had the highest number of government- and mixed-source documents. Figure 7 summarizes the most abundant mixed sources of eight government combinations identified. Documents generated by governments and universities were the most abundant mixed-source documents followed by federal government and regional government collaborations. 


\section{Discussion}

Proactive coastal policy planning can save major long-terms costs that are otherwise amplified by a lack of integrated adaptation planning. Although many communities share potential for climate-related hazards, relevant climate adaptation options often do not manifest until after a major event occurs if at all $[4,8,28,34]$. This reinforces the importance of information provision across all sectors, especially when applied. There are numerous, well-resourced web information portals now that offer adaptation reports and many other resources, (e.g., NOAA's Digital Coasts, Surging Seas, Climate Adaptation Knowledge Exchange, Coastal Climate Adaptation Library). Detailed criteria for assessing adaptation websites in terms of informational, relational, and systems functions are emerging (e.g., [23]).

\subsection{Climate Adaptation and Roles of Grey Literature}

Effective climate policy development requires applied technical and applied policy information in areas subject to sea level rise and other coastal climate changes (e.g., increased flooding, precipitation changes) for decadal-scale planning. This search exceeded the number of academic databases that are typically examined in this policy realm, characterizing applied policy with a review of adaptation literature that also included government, NGO, university, and mixed-source adaptation documents; the "grey literature" not returned in searches of academic databases (journals).

We found a large non-academic literature of government, NGO, university, and business reports on adaptation (Figures 4, 6 and 7), often highly applied and not available in academic-only reviews. $53 \%$ of the literature identified was from academic journal databases with these sources: government $21 \%$, university $10 \%$, NGOs $8 \%$, and mixed-source documents $14 \%$. Produced by government agencies and NGOs, this literature does not appear in academic journal databases though numbering in the dozens to hundreds of applied documents for many cities and sub-regions of the U.S. Atlantic coast and in the thousands of documents internationally (e.g., Virtual Climate Adaptation Library). In many regions, academic journal documents can be the tip of the iceberg. Adaptation planning at several governance scales for policymakers, engineers, and scientists should benefit from broader recognition of institutional reports termed "practitioner-generated research" [35]. Further rationale and information in Reference [24] reinforces the value of grey literature and all-source databases, in addition to academic databases.

At the interface of governance and community planning, we focused on stratifying primary subcategories of governance at four scales: GF: government federal, GS: government state, GR: government regional, GL: government local. There were more state-sourced reports than any other scale, reflecting the applied importance of climate adaptation to many state-level agencies (Figure 7). These non-academic documents can be very applied and often have diverse mixtures of sources (e.g., government $x$ university) reflecting on institutional relationships and power structures that help determine the trajectories of social-ecological systems [30,36]. Many of these reports reflect direct partnerships among state agencies (e.g., New York and New Jersey, and North Carolina and South Carolina state agency partnerships). We excluded the mixed-state reports returned in our searches (Supplementary Table S1) to not confound state-level analyses, but reports with multiple state sources are another scale of analysis for future research. Governments and other sources of quality adaptation case-studies can be very fundamental gatekeepers for policy-relevant information (Figure 7). Much of this information is not retrieved in searches of academic databases.

Despite the comprehensive nature of many systematic reviews, some categories of relevant literature are typically unsampled. For example, we did not directly sample the growing legal literature on climate adaptation (e.g., using LexisNexis searches), many systematic adaptation reviews do not. These databases will grow in importance to both administrative and case law as the effects of sea level rise and other coastal changes accumulate during the century. The same applies in terms of the coastal business literature (e.g., tourism, real estate) which can overlap with coastal engineering reports. In several relevant coastal science and engineering disciplines, conference proceedings have 
relevant papers that are not indexed in academic databases. A variety of reports from conference proceedings can also be found in all-source databases.

Book chapters by academic publishers are typically also missed in academic database searches. A book on coastal climate adaptation can have many chapters specific to individual regions and topics but these chapters are often not treated as stand-alone papers by academic databases and can be lost to searches restricted to journal databases. In addition, there are climate planning documents of complete relevance to the east coast of the U.S. that would not be returned by this type of search because they were national-scale reports and wouldn't surface under specific state names. There are also government, university, nonprofit, and mixed-source literatures from a number of regional and sub-regional adaptation collaborations among institutions from several sectors (Figure 7). Other examples in Reference [37] involve university, state government, and nonprofit reports that are also not archived or searchable in academic databases.

The sampling universe for the interdisciplinarity represented by the coastal climate adaptation literature is much more diverse than found in academic databases. Policy planning and actions on climate adaptation policy issues across many fields would benefit from the inclusion of all-source databases in addition to academic databases in knowledge transfer and literature reviews.

\subsection{U.S. Atlantic Coast Geographic Comparisons}

Life in all Atlantic coast states is associated with the coasts, the source of invaluable natural, social and economic capital. A still growing number of citizens in Florida and the Carolinas live in coastal counties, with similar patterns in the northeast U.S. (NOAA, 2013). There are several opportunities to compare climate adaptation across separate regions of the eastern U.S. $[12,38]$ with applications to governance at all scales.

\subsubsection{Southeast U.S.}

The literature on Florida coastal policy and climate adaptation continues to increase (Figures 4 and 5). Academic database examples include, e.g., References [36,39-41]. There is also a large grey literature of substantial applied policy value from government, university and nonprofit sources (Figure 6). This literature includes important government reports (e.g., [42]) and mixed-source reports [43]. Many often-underemphasized efforts are underway in Florida coastal city and county governments to build adaptation planning into governance [44,45].

The Carolinas sub-region also has a substantial academic literature of policy relevance with works on adaptation opportunity windows, stakeholder networks, cross-sectorial information paths, mainstreaming of best practices in adaptation and related themes (e.g., [29,46-48]). The Carolinas also have valuable non-academic literature including important government, NGO and mixed-source reports (e.g., $[49,50])$.

\subsubsection{Northeast U.S.}

New York state had a solid literature on climate adaptation before Hurricane Sandy in 2011, much at the New York City scale, with continuing state and local output after. The numbers of reports in New Jersey rose substantially after Sandy (Figure 4). New York had 57 academic reports and 12 all-source reports in contrast to Florida which had 72 all-source and 54 academic reports (Figure 4), reflecting a greater relative academic focus on adaptation (e.g., [51]). Both states also have valuable grey literatures based on government and university reports (Figure 6).

Of the five New England coastal states, Massachusetts had a substantially larger climate adaptation literature. Relative to the other states, the Massachusetts literature increased noticeably after Hurricane Sandy (Figure 5). Academic examples include References [52,53], from Massachusetts and Rhode Island, respectively. New England states have valuable grey literatures based on government, NGO and mixed-source reports (Figure 6). 


\subsection{Limitations on Geographic Comparisons}

The project was based in Florida and much of non-academic literature identified from the searches was from a database with over 2500 global adaptation references maintained by the study team (VCAL, renamed the Coastal Climate Adaptation Library in winter 2018) which has, in part, a Florida focus due to team work on applied coastal management in that state. The number of academic and non-academic documents identified from Florida was higher at state levels (Figure 4). We may have under-sampled NY, NJ and ME, particularly in terms of the grey literature generated by many robust partnerships among government agencies, university consultants, NGOs, and mixed combinations of these sources. In addition, the total number of papers would have been substantially higher if Georgia was included in the search (e.g., with examples of adaptation planning including Reference [54]).

\subsection{Coastal Adaptation Policy among Institutional Sectors}

Coastal climate adaptation can be pre-event (proactive planning) or post-event (reactive; disaster response, economic constraints amplified), or a mix of both when communities learn from prior disasters. In many regions, coastal adaptation planning is largely reactive rather than proactive with diverse reasons [8] and varying implications for society and long-term economic and socio-cultural systems $[7,55,56]$. A mechanism to broach these system traps is to illuminate adaptation decision-making with not only good theory but also unusually applied case-studies often not sourced by academic journals and not found in academic databases.

The differing categories of document sources examined here represent proxies for differing institutional sectors. We examined six sectors within the coastal climate adaptation literature including governments at four scales within, NGOs, universities, and also mixed-source reports with combinations of all of these sectors. A common theme for all sectors is implementation: "Adaptation planning is occurring in the public and private sectors and at all levels of government but few measures have been implemented." [28]. Non-academic documents, not in academic databases, often show the inner workings of city through federal governance, or local through national NGO planning, or mixed-sector reports often with universities. These documents can be applied windows into implementation.

The findings can provide a basis for theoretically sound approaches that also are grounded in real-world implementation experiences to better understand the role of communications and the actual implementation of politically complicated adaptation. Communications, psychology, and socio-cultural norms are a major component of societal responses to adaptation [57,58] and related ideas should be examined; e.g., how a good flyer can penetrate audiences more effectively than a 50-page technical report?

Avenues for productive additional research could involve projects that assess the relative impacts of these papers using new impact measures, in addition to solely academic impact metrics. Specifically, metrics that measure actual adaptation implementation factors and use multiple criteria, including natural and social capital, in addition to only economic capital. Comparisons of direct impact of applied adaptation should consider academic measures of impact factor but may be more directly measured by implementation-centric "impact measures". Examples could include the number of projects started or numbers of hectares of land into conservation status (e.g., Florida Forever funds for key coastal land acquisitions, recently unfunded).

A related issue involves how the sector/source of the document influences its readership and potential implementation. Comparisons could involve academic documents vs. state agency vs. NGO reports, etc. A common theme in some sub-regions (Florida, the Carolinas) is that adaptation ultimately has to be local, as the state and federal government will not treat the issue with consistency. Other research could focus temporally on trends in recommendations by year or decade to assess how accurate those recommendations were and to what degree they were implemented.

The applications of more use of government, NGO, and university reports are potentially abundant. Most managers and decision-makers are buried under already dense information 
loads, yet, the instructive value of on-the-ground practice is higher than ever. This value can be measured in real manners if mistakes in long-term planning are made, and even repeated. The alternatives are preferred and will be associated with full flows of information from all sectors across all spatial scales.

\section{Conclusions}

Comprehensive reviews of academic and non-academic adaptation databases identified diverse sources of policy information not returned in searches of academic databases including: government, NGO, university, and mixed-source documents. These relatively hidden documents involve multiple government, NGO, university and business sources and provide insight into on-the-ground innovations, institutional relationships, and power structures across multiple spatial scales. This broader literature should be included in more adaptation reviews: there are applications at national, state, regional and local scales. There were more state-sourced reports than any other governance scale, reflecting the importance of adaptation to many state-level agencies despite spatially variable political constraints. Much climate adaptation information of value is not retrieved by searches of academic databases alone. This grey literature can be rich in applied adaptation knowledge, including on-the-ground coastal engineering case-studies and government policy experiments across important scales of geography and governance.

Supplementary Materials: The following are available online at http:/ /www.mdpi.com/2077-1312/6/4/152/s1, Table S1. Inclusion and exclusion criteria for literature searches in present study; Table S2. Documents included in the analysis; Table S3. Observed and expected frequencies by sub-region and type of database; Table S4. Observed and expected frequencies by region and document source.

Author Contributions: Conceptualization, K.L., C.G. and B.B.; Methodology, K.L., C.G. and B.B.; Formal Analysis, C.G., K.L. and B.B.; Data Curation, C.G. and B.B.; Funding Acquisition, K.L.; Writing, K.L., C.G. and B.B.; Project Administration, K.L.

Funding: Portions of this project were funded by the NOAA Climate Program Office Award NA11OAR43101, Advanced Regional \& Decadal Predictions of Coastal Inundation for the U.S. Atlantic \& Gulf Coasts, Ben Horton, Rutgers Univ., P.I. Additional funding was provided by Coastal Science and Policy, Inc. The APC was funded by the Open Access Subvention Fund and the Florida Tech Libraries.

Acknowledgments: We thank the following for comments or other assistance with this work: B. Horton and S. Lucas, also E. Ariza, J. Fergus, A. Lindeman, H. Wanless, R. Parkinson, E. Schoppaul and R. Sippel. We thank the following F.I.T. students who have worked on the Virtual Climate Adaptation Library: A. Averett, A. Castenada, L. Dame, M. Eyjolfstottdir, M. Farley, A. Hijazi, M. Phelan, M. Wilson, and H. Yu.

Conflicts of Interest: The authors declare no conflicts of interest. The funders had no role in the design of the study; in the collection, analyses, or interpretation of data; in the writing of the manuscript, and in the decision to publish the results.

\section{References}

1. Tebaldi, C.; Strauss, B.H.; Zervas, C.E. Modelling sea level rise impacts on storm surges along US coasts. Environ. Res. Lett. 2012, 7, 014032. [CrossRef]

2. Hsiang, S.; Kopp, R.; Jina, A.; Rising, J.; Delgado, M.; Mohan, S.; Rasmussen, D.J.; Muir-Wood, R.; Wilson, P.; Oppenheimer, M.; et al. Estimating economic damage from climate change in the United States. Science 2017, 356, 1362-1369. [CrossRef] [PubMed]

3. International Monetary Fund. Report for Selected Country Groups and Subjects; World Econ. Outlook; International Monetary Fund: Washington, DC, USA, April 2016.

4. Kulp, S.; Strauss, B.H. Rapid escalation of coastal flood exposure in US municipalities from sea level rise. Clim. Chang. 2017, 142, 477-489. [CrossRef]

5. Jones, L.; Champalle, C.; Chesterman, S.; Cramer, L.; Crane, T.A. Constraining and enabling factors to using long-term climate information in decision-making. Clim. Policy 2017, 17, 551-572. [CrossRef]

6. Snover, A.K.; Binder, L.C.W.; Lopez, J.; Willmott, E.; Kay, J.E.; Howell, D.; Simmonds, J. Preparing for Climate Change: A Guidebook for Local, Regional, and State Governments; University of Washington: King County, WA, USA; ICLEI: Seattle, WA, USA, 2007. 
7. Kunreuther, H.C.; Michel-Kerjan, E.O. At War with the Weather: Managing Large-Scale Risks in a New Era of Catastrophes; MIT Press: Cambridge, MA, USA, 2009.

8. Moser, S.C.; Williams, S.J.; Boesch, D.F. Wicked challenges at lands' end: Managing coastal vulnerability under climate change. Annu. Rev. Environ. Res. 2012, 37, 51-78. [CrossRef]

9. Hauer, M.E.; Evans, J.M.; Mishra, D.R. Millions projected to be at risk from sea-level rise in the continental United States. Nat. Clim. Chang. 2016, 6, 691-695. [CrossRef]

10. Sullivan Sealey, K.S.; Binder, P.M.; Burch, R.K. Financial credit drives urban land-use change in the United States. Anthropocene 2018, 21, 42-51. [CrossRef]

11. Lemos, M.C.; Kirchhoff, C.J.; Ramprasad, V. Narrowing the climate information usability gap. Nat. Clim. Chang. 2012, 2, 789-794. [CrossRef]

12. Dilling, L.; Lackstrom, K.; Haywood, B.; Dow, K.; Lemos, M.C.; Berggren, J.; Kalafatis, S. What stakeholder needs tell us about enabling adaptive capacity: The intersection of context and information provision across regions in the United States. Weather Clim. Soc. 2015, 7, 5-17. [CrossRef]

13. Berrang-Ford, L.; Pearce, T.; Ford, J.D. Systematic review approaches for climate change adaptation research. Reg. Environ. Chang. 2015, 15, 755-769. [CrossRef]

14. Vink, M.J.; Dewulf, A.; Termeer, C. The role of knowledge and power in climate change adaptation governance: A systematic literature review. Ecol. Soc. 2014, 18, 46. [CrossRef]

15. Sierra-Correa, P.C.; Kintz, J.R.C. Ecosystem-based adaptation for improving coastal planning for sea-level rise: A systematic review for mangrove coasts. Mar. Policy 2015, 51, 385-393. [CrossRef]

16. McDowell, G.; Ford, J.; Jones, J. Community-level climate change vulnerability research: Trends, progress, and future directions. Environ. Res. Lett. 2016, 11, 033001. [CrossRef]

17. Räsänen, A.; Juhola, S.; Nygren, A.; Käkönen, M.; Kallio, M.; Monge, A.M.; Kanninen, M. Climate change, multiple stressors and human vulnerability: A systematic review. Reg. Environ. Chang. 2016, 16, 2291-2302.

18. Ford, J.D.; Berrang-Ford, L.; Paterson, J. A systematic review of observed climate change adaptation in developed nations. Clim. Chang. 2011, 106, 327-336. [CrossRef]

19. Antwi-Agyei, P.; Dougill, A.J.; Stringer, L.C. Barriers to climate change adaptation: Evidence from northeast Ghana in the context of a systematic literature review. Clim. Dev. 2014, 7, 297-309. [CrossRef]

20. Ford, J.D.; Pearce, T. What we know, do not know, and need to know about climate change vulnerability in the western Canadian Arctic: A systematic literature review. Environ. Res. Lett. 2010, 5, 014008. [CrossRef]

21. Porter, J.J.; Dessai, S.; Tompkins, E.L. What do we know about UK household adaptation to climate change? A systematic review. Clim. Chang. 2014, 127, 371-379. [CrossRef]

22. Sanderson, H.; Hilden, M.; Russel, D.; Dessai, S. Database support for adaptation to climate change: An assessment of web-based portals across scales. Integr. Environ. Assess. Manag. 2016, 12, 627-631. [CrossRef]

23. Mitchell, C.L.; Burch, S.L.; Driscoll, P.A. (Mis) communicating climate change? Why online adaptation databases may fail to catalyze adaptation action. Wiley Interdiscip. Rev. Clim Chang. 2016, 7, 600-613. [CrossRef]

24. Lawrence, A.; Thomas, J.; Houghton, J.; Weldon, P. Collecting the evidence: Improving access to grey literature and data for public policy and practice. Aust. Acad. Res. Libr. 2015, 46, 229-249. [CrossRef]

25. Adams, R.J.; Smart, P.; Huff, A.S. Shades of grey: Guidelines for working with the grey literature in systematic reviews for management and organizational studies. Int. J. Manag. Rev. 2017, 19, 432-454. [CrossRef]

26. Pearce, T.; Ford, J.D.; Duerden, F.; Smit, B.; Andrachuk, M.; Berrang-Ford, L.; Smith, T. Advancing adaptation planning for climate change in the Inuvialuit Settlement Region (ISR): A review and critique. Reg. Environ. Chang. 2011, 11,1-17. [CrossRef]

27. Bloetscher, F.; Meeroff, D.E.; Heimlich, B.N. Improving the Resilience of a Municipal Water Utility Against the Likely Impacts of Climate Change: A Case Study: City of Pompano Beach Water Utility; Florida Atlantic University: Boca Raton, FL, USA, 2009.

28. Melillo, J.M.; Richmond, T.; Yohe, G.W. (Eds.) Climate Change Impacts in the United States: The Third National Climate Assessment; US Global Change Research Program: Washington, DC, USA, 2014; p. 841. [CrossRef]

29. Haywood, B.K.; Brennan, A.; Dow, K.; Kettle, N.P.; Lackstrom, K. Negotiating a mainstreaming spectrum: Climate change response and communication in the Carolinas. J. Environ. Policy Plan. 2014, 16, 75-94. [CrossRef] 
30. Berkes, F.; Colding, J.; Folke, C. (Eds.) Navigating Social-Ecological Systems: Building Resilience for Complexity and Change; Cambridge University Press: Cambridge, UK, 2008.

31. Jamil, T.; Ly, A.; Morey, R.D.; Love, J.; Marsman, M.; Wagenmakers, E.J. Default “Gunel and Dickey” Bayes factors for contingency tables. Behav. Res. Methods 2015, 49, 638-652. [CrossRef] [PubMed]

32. Cohen, J. Statistical Power Analysis for the Behavioral Sciences, 2nd ed.; Psychology Press: New York, NY, USA, 1988.

33. Barth, M.C.; Titus, J.G. Greenhouse Effect and Sea Level Rise: A Challenge for this Generation; Van Nostrand Reinhold Co.: New York, NY, USA, 1984; 325p.

34. Noss, R.F. Between the devil and the deep blue sea: Florida's unenviable position with respect to sea level rise. Clim. Chang. 2011, 107, 1-16. [CrossRef]

35. Haddaway, N.R.; Bayliss, H.R. Shades of grey: Two forms of grey literature important for reviews in conservation. Biol. Conserv. 2015, 191, 827-829. [CrossRef]

36. Ariza, E.; Lindeman, K.C.; Mozumder, P.; Suman, D.O. Beach management in Florida: Assessing stakeholder perceptions on governance. Ocean Coast. Manag. 2014, 96, 82-93. [CrossRef]

37. Susskind, D.; Rumore, D.; Hulet, C.; Field, P. Managing Climate Risks in Coastal Communities: Strategies for Engagement, Readiness and Adaptation; Anthem Environment and Sustainability; Anthem Press: London, UK, 2015; 464p.

38. Lindeman, K.C.; Dame, L.E.; Avenarius, C.B.; Horton, B.P.; Donnelly, J.P.; Corbett, D.R.; Kemp, A.C.; Lane, P.; Mann, M.E.; Peltier, W.R. Science needs for sea-level adaptation planning: Comparisons among three U.S. Atlantic coastal regions. Coast. Manag. 2015, 43, 555-574. [CrossRef]

39. Martin, J.; Fackler, P.L.; Nichols, J.D.; Lubow, B.C.; Eaton, M.J.; Runge, M.C.; Stith, B.M.; Langtimm, C.A. Structured decision making as a proactive approach to dealing with sea level rise in Florida. Clim. Chang. 2011, 107, 185-202. [CrossRef]

40. Boda, C.S. Power and rationality in coastal planning: Effects on participation and possibility in the management of barrier island dunes in Flagler Beach, Florida, USA. J. Coast. Conserv. 2015, 19, 561-576. [CrossRef]

41. Mozumder, P.; Flugman, E.; Randhir, T. Adaptation behavior in the face of global climate change: Survey responses from experts and decision makers serving the Florida Keys. Ocean Coast. Manag. 2011, 54, 37-44. [CrossRef]

42. Southeast Florida Regional Climate Change Compact (SFRCCC). Analysis of the Vulnerability of Southeast Florida to Sea Level Rise; SFRCCC Inundation Mapping and Vulnerability Assessment Work Group: Miami, FL, USA, 2012.

43. USGS; FAU; FSG. Predicting Ecological Changes in the Florida Everglades under a Future Climate Scenario; Florida Sea Grant, and Florida Atlantic University Report; U.S Geological Survey: Reston, VA, USA, 2013.

44. Butler, W.H.; Deyle, R.E.; Mutnansky, C. Low-regrets incrementalism: Land use planning adaptation to accelerating sea level rise in Florida's Coastal Communities. J. Plan. Educ. Res. 2016, 36, 319-332. [CrossRef]

45. Calil, J.; Newkirk, S. Aligning Natural Resource Conservation, Flood Hazard Mitigation, and Social Vulnerability Remediation in Florida. J. Ocean Coast. Econ. 2017, 4, 1-29. [CrossRef]

46. Poulter, B.; Feldman, R.L.; Brinson, M.M.; Horton, B.P.; Orbach, M.K.; Pearsall, S.H.; Reyes, E.; Riggs, S.R.; Whitehead, J.C. Sea-level rise research and dialogue in North Carolina: Creating windows for policy change. Ocean Coast. Manag. 2009, 52, 147-153. [CrossRef]

47. Dow, K.; Haywood, B.K.; Kettle, N.P.; Lackstrom, K. The role of ad hoc networks in supporting climate change adaptation: A case study from the Southeastern United States. Reg. Environ. Chang. 2013, 13, 1235-1244. [CrossRef]

48. Lackstrom, K.; Kettle, N.P.; Haywood, B.; Dow, K. Climate-sensitive decisions and time frames: A cross-sectoral analysis of information pathways in the Carolinas. Weather Clim. Soc. 2014, 6, 238-252. [CrossRef]

49. North Carolina Interagency Leadership Team (NCILT). Climate Ready North Carolina: Building a Resilient Future; North Carolina Interagency Leadership Team: Raleigh, NC, USA, 2012.

50. CH2MHILL; EPA. Community Resilience Project in Wilmington, NC; EPA Office of Community Sustainability: Wilmington, NC, USA, 2013; 50p.

51. Rosenzweig, C.; Solecki, W. Introduction to climate change adaptation in New York City: Building a risk management response. Ann. N. Y. Acad. Sci. 2010, 1196, 13-18. [CrossRef] [PubMed]

52. Hamin, E.M.; Gurran, N.; Emlinger, A.M. Barriers to municipal climate adaptation: Examples from coastal Massachusetts' smaller cities and towns. J. Am. Plan. Assoc. 2014, 80, 110-122. [CrossRef] 
53. Becker, A. Using boundary objects to stimulate transformational thinking: Storm resilience for the Port of Providence, Rhode Island (USA). Sustain. Sci. 2016, 12, 477-501. [CrossRef]

54. Hauer, M.E.; Evans, J.M.; Alexander, C.R. Sea-level rise and sub-county population projections in coastal Georgia. Popul. Environ. 2015, 37, 44-62. [CrossRef]

55. Wise, R.M.; Fazey, I.; Smith, M.S.; Park, S.E.; Eakin, H.C.; Van Garderen, E.A.; Campbell, B. Reconceptualising adaptation to climate change as part of pathways of change and response. Glob. Environ. Chang. 2014, 28, 325-336. [CrossRef]

56. Kantamaneni, K.; Phillips, M.; Thomas, T.; Jenkins, R. Assessing coastal vulnerability: Development of a combined physical and economic index. Ocean Coast. Manag. 2018, 158, 164-175. [CrossRef]

57. Kahan, D.M.; Peters, E.; Wittlin, M.; Slovic, P.; Ouellette, L.L.; Braman, D.; Mandel, G. The polarizing impact of science literacy and numeracy on perceived climate change risks. Nat. Clim. Chang. 2012, 2, 732-735. [CrossRef]

58. Van der Linden, S.; Maibach, E.; Leiserowitz, A. Improving public engagement with climate change: Five "best practice" insights from psychological science. Perspect. Psychol. Sci. 2015, 10, 758-763. [CrossRef] [PubMed]

(C) 2018 by the authors. Licensee MDPI, Basel, Switzerland. This article is an open access article distributed under the terms and conditions of the Creative Commons Attribution (CC BY) license (http://creativecommons.org/licenses/by/4.0/). 